\title{
SAXS investigation of un-etched and etched ion tracks in polycarbonate
}

U. H. Hossain ${ }^{*}$, M. D. Rodriguez ${ }^{1}$, D. Schauries ${ }^{1}$, A. Hadley ${ }^{1}$, M. Schleberger ${ }^{2}$, C. Trautmann $^{3,4}$, S. Mudie ${ }^{5}$, and P. Kluth ${ }^{1}$

${ }^{1}$ Department of Electronic Materials Engineering, Research School of Physics and Engineering, Australian National University, Canberra, ACT 2601, Australia

${ }^{2}$ Fakultät für Physik and CENIDE, Universität Duisburg-Essen, 47057 Duisburg, Germany

${ }^{3}$ GSI Helmholtz Centre for Heavy Ion Research, Planckstrasse 1, 64291 Darmstadt, Germany

${ }^{4}$ Technische Universität Darmstadt, 64287 Darmstadt, Germany

${ }^{5}$ Australian Synchrotron, 800 Blackburn Road, Clayton, VIC 3168, Australia

* Corresponding author: Umme Habiba Hossain

eMail: $\quad$ habiba.hossain@anu.edu.au

Phone: $\quad+61261257261$

\begin{abstract}
Investigation of the ion track morphologies and track etching behaviour in polycarbonate (PC) films was carried out using synchrotron based small-angle x-ray scattering (SAXS) measurements. The tracks were induced by $\mathrm{Au}$ ions with kinetic energies of 1.7 and $2.2 \mathrm{GeV}$ with applied fluences between $1 \times 10^{10}$ and $1 \times 10^{12} \mathrm{ions} / \mathrm{cm}^{2}$. The average radii of the un-etched tracks were studied as a function of the irradiation fluence, indicating a general ion induced degradation of the polymer with a simultaneous increase in ion track radius from $2.6 \pm 0.02 \mathrm{~nm}$ to $3.4 \pm 0.3 \mathrm{~nm}$. Chemical etching of the ion tracks in PC leads to the formation of cylindrical pores. The pore radius increases linearly with etching time. In $3 \mathrm{M} \mathrm{NaOH}$ at $55^{\circ} \mathrm{C}$, a radial etching rate of $9.2 \mathrm{~nm} / \mathrm{min}$ is observed.
\end{abstract}

\section{Keywords}

Small-angle x-ray scattering (SAXS), polycarbonate (PC), swift heavy ion tracks, radiation degradation 


\section{Introduction}

When a polymeric material is exposed to heavy ion beams in the $\mathrm{MeV}-\mathrm{GeV}$ energy region, the ions pass through the material nearly un-deflected and lose their energy by intense electronic excitation and ionization processes around the ion trajectory. The result is a narrow damage trail around the ion path. These so called "ion tracks" are typically a few nanometres in diameter and tens of micrometres in length [1]. In many polymers, ion tracks show increased susceptibility to chemical etching compared to the undamaged material. Ion Track Technology makes use of chemical track etching for many applications such as the production of nanoporous filters, micro-capacitors, diodes and templates for nanowires for microelectronic devices and sensors [2- 4].

Polycarbonate (PC) is a polymer with a carbonate group attached to the aromatic ring, and is well known for its excellent thermal and chemical stability as well as its exceptional mechanical properties. It is established as a very useful material for hi-tech and biological applications $[5,6]$. The chemical structure of $\mathrm{PC}$ with its ester and aromatic rings is shown in Figure 1.

Experiments on ion tracks in polymers were carried out by several groups [7] exposing them to protons, electrons, and ions. For example, Joshi et al. studied PC irradiated with Fe ions (60 and $120 \mathrm{MeV}$ ) for anti-bacterial properties and found chain scission at the carbonate group of PC [8]. Asad Ali et al. irradiated PC with $95-\mathrm{MeV} \mathrm{O}^{6+}$ ion and showed the chain scission of C$\mathrm{O}$ bonds of carbonate and the formation of phenolic O-H bonds [9]. Singh et al. investigated PC under $\mathrm{Cu}$ and $\mathrm{Ni}$ ion irradiation and found that there was an increase of degradation crosssection of chemical groups with the increase in electronic energy loss $(\mathrm{dE} / \mathrm{dx})[10]$. Dehaye et al. presented chemical modifications of PC comparing the effect of beams of low and high $\mathrm{dE} / \mathrm{dx}$, indicating the chemical mechanisms are different in the two energy deposition regimes [11]. Steckenreiter et al. reported on the chemical nature of $720-\mathrm{MeV} \mathrm{Kr}$ ion induced modification in PC analysed by FT-IR spectroscopy and found a new absorption band of the alkyne end group (-C $\equiv \mathrm{C}-)$ [12]. To summarise the findings, the main ion-induced modifications of PC are chain scissoring, chemical decomposition as well as outgasing of volatile degradation fragments [13], which in all are responsible for the increased etching rate. Previous characterization of ion tracks in PC predominantly probed bulk properties, such as using Fourier-transform-infrared spectroscopy (FT-IR) and x-ray diffraction (XRD) to estimate the structural change of materials. The ion track size is typically estimated by following the 
ratio between the damaged and pristine fraction of the polymer as a function of fluence. While these investigations on ion beam effects on PC yield important information about the track formation mechanisms, there is still an incomplete understanding of the process and the track sizes in PC.

Small-angle x-ray scattering (SAXS) is well suited to analysing ion tracks in inorganic solid materials such as silica, natural minerals, and amorphous Si and Ge [9]. The technique has also been successfully applied to study ion tracks [20] and track etched nano-pores [21] in polymer materials, demonstrating its ability to determine the track radius in polymers.

In this paper, we are presenting a synchrotron-based SAXS investigation on the size of etched and unetched ion tracks produced by irradiating PC foils with high-energy Au ions.

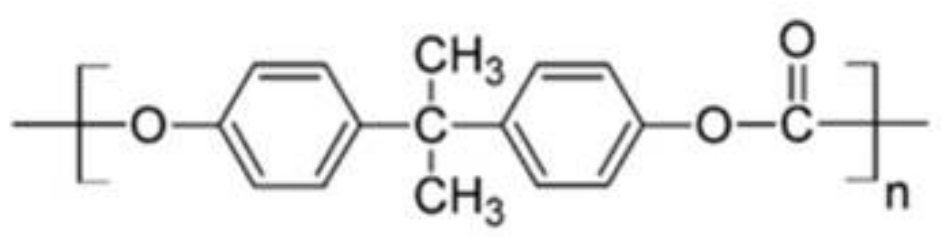

Figure. 1: Schematic presentation of the structure of PC

\section{Experimental}

We used commercially available polycarbonate PC $\left(1.2 \mathrm{gm} / \mathrm{cm}^{3}\right)$ foils with a thickness of 10 $\mu \mathrm{m}$ and $30 \mu \mathrm{m}$ (Makrofol), supplied by Bayer Material Science AG.

The samples were irradiated at the Universal Linear Accelerator (UNILAC) at the GSI Helmholtz Centre for Heavy Ion Research in Darmstadt, Germany with 8.4 and $11.4 \mathrm{MeV} / \mathrm{u}$ $\mathrm{Au}$ (atomic mass $197 \mathrm{u}$, total kinetic energy 1.7 and $2.2 \mathrm{GeV}$ ) ions using fluences between $1 \times 10^{10}-$ and $1 \times 10^{12}$ ions $/ \mathrm{cm}^{2}$. The SRIM 2010 software [22] was used to calculate the average projected ranges of the projectiles in polymers, which exceeds $130 \mu \mathrm{m}$ for $1.7 \mathrm{GeV}$ and 175 $\mu \mathrm{m}$ for $2.2 \mathrm{GeV} \mathrm{Au}$ ions and, therefore, the ions tracks extend throughout the entire polymer thickness. The calculated electronic energy loss $\mathrm{dE} / \mathrm{dx}$ per unit length of the ion trajectory of $\mathrm{Au}$ ions is approximately $13.4 \mathrm{MeV} / \mu \mathrm{m}$ and $12.7 \mathrm{MeV} / \mu \mathrm{m}$ for $1.7 \mathrm{GeV}$ and $2.2 \mathrm{GeV} \mathrm{Au}$ ions, respectively. Over the depth of the $30 \mu \mathrm{m}$ and $10 \mu \mathrm{m}$ thick PC samples, the energy loss changes by less than $5 \%$ and $1 \%$, respectively.

For the etching experiments, the heavy ion irradiated polymer foils $(30 \mu \mathrm{m})$ were immersed in $3 \mathrm{M}$ sodium hydroxide $(\mathrm{NaOH})$ solutions at $55^{\circ} \mathrm{C}$. The etching process was performed for 
different etching times (between 1 and $12 \mathrm{~min}$ ). After etching, the samples were rinsed in deionized water.

The diameter of the ion tracks and track-etched pores was determined by SAXS. It is important to mention that all samples were etched just before the x-ray experiments. The measurements were performed at the SAXS/WAXS beamline of the Australian Synchrotron in Melbourne, Australia. Measurements were carried out with $12 \mathrm{keV}$ x-rays and a beam-spot size of 0.04 $\mathrm{mm}^{2}$. Images were collected with a Pilatus $1 \mathrm{M}$ detector at a single camera length of $1.6 \mathrm{~m}$.

\section{Results and discussion}

SAXS detector images for PC $(10 \mu \mathrm{m})$ in pristine condition (a) irradiated with $1.7 \mathrm{MeV} \mathrm{Au}$ ions to a fluence of $5 \times 10^{10} \mathrm{~cm}^{-2}$ (b) and after etching for $7 \mathrm{~min}$ (c) are shown in Figure 2 . Compared with the pristine sample, the irradiated sample shows two slightly bent streaks. This anisotropic scattering occurs, when the ion tracks are tilted with respect to the x-ray beam due to their high aspect ratio [23-25]. The scattering intensities within the streaks were isolated by exclusively selecting the q-range around the streaks in the SAXS detector image and then integrating the intensity radially to obtain the 1-dimensional SAXS intensity as a function of the scattering vector $q=|\vec{q}|$. Afterwards, the pattern of the pristine sample was subtracted for background removal. In the SAXS images with multiple streaks (e.g. Fig. 2(b)) identical scattering patterns were found when isolating individual streaks.

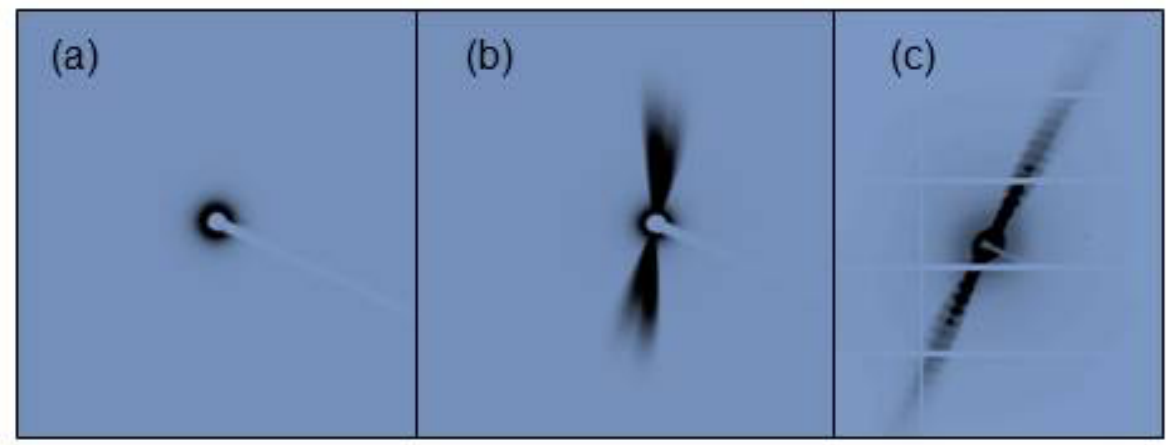


Fig. 2: SAXS detector images for PC a) before irradiation $b$ ) after irradiation at a fluence of $3 \times 10^{11}$ ions $/ \mathrm{cm}^{2}$ using $1.7 \mathrm{Gev} \mathrm{Au}$ ions, and c) after etching ( $7 \mathrm{~min}$ ), irradiation at a fluence of $5 \times 10^{10}$ ions $/ \mathrm{cm}^{2}$ using $2.2 \mathrm{GeV}$ Au ions. Dark colours correspond to high scattering intensities.

Figure 3 shows the SAXS scattering intensities for irradiations with $1.7 \mathrm{GeV} \mathrm{Au}$ ions with fluences between $1 \times 10^{10}$ and $1 \times 10^{12}$ ions $/ \mathrm{cm}^{2}$ as a function of the scattering vector $|\vec{q}|$ (without chemical etching). The scattering patterns were modelled by approximating the ion tracks as cylinders with constant density. The cylinder approximation is justified by the nearly constant energy loss throughout the sample thickness. The corresponding form factor is:

$$
f(q, R)=2 \pi R^{2} L \Delta \rho \frac{J_{1}(q R)}{q R}
$$

with radius $R$, track length $L$, change in electron density $\Delta \rho$ and $J_{1}(x)$ representing the first order Bessel function. The scattering intensity is proportional to the square of the form factor. A narrow normal distribution with widths $\sigma$ is assumed to account for deviation of the track geometry from a perfect cylinder. Furthermore, the roughness along the track interface is modelled by an exponential dampening of the scattering intensity with a roughness parameter $\sigma_{\mathrm{D}}[26]$.

$$
I=\int|f(q, R)|^{2} g(\sigma, R) e^{-\sigma_{D}^{2} q^{2}} \mathrm{~d} R
$$

The radius measured by SAXS in this work represents the average value over the entire polymer thickness. A least-squares algorithm was used to fit the SAXS pattern with the cylinder model. For each pattern the fit (shown as solid lines in Fig. 3) yields a value for the track radius, polydispersity and roughness. The fits shown in Fig. 3 are in excellent agreement with the SAXS patterns. 


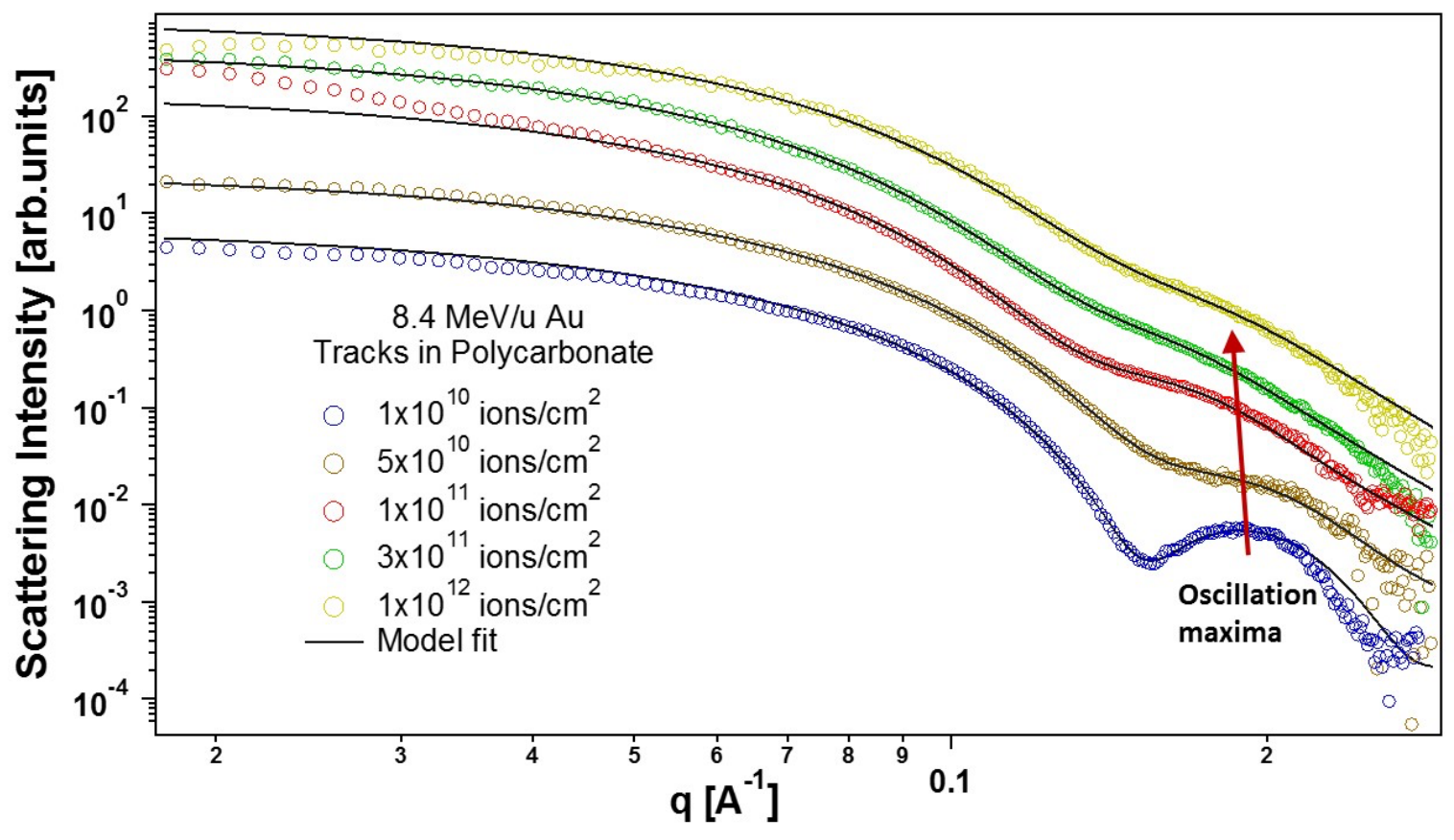

Fig. 3: SAXS patterns and corresponding fits (solid lines) for PC irradiated with $1.7 \mathrm{GeV} \mathrm{Au}$ at different fluences (without chemical etching). An arrow indicates the oscillation maxima shift towards smaller q.

Depending on the fluence, a variation in the shape of the scattering pattern is observed. The "strongest" oscillations appear at low fluence. With increasing fluence, the SAXS pattern displays a shift of the oscillation maxima towards smaller $\mathrm{q}$, indicating an increase in the average track size, and the oscillations become weaker, but are still clearly recognizable. Based on Eq. 2, the fits yield a track radius of $3.4 \pm 0.03 \mathrm{~nm}$ at $1 \times 10^{12} \mathrm{ions} / \mathrm{cm}^{2}$, and $2.6 \pm 0.02$ $\mathrm{nm}$ at $1 \times 10^{10}$ ions $/ \mathrm{cm}^{2}$. 


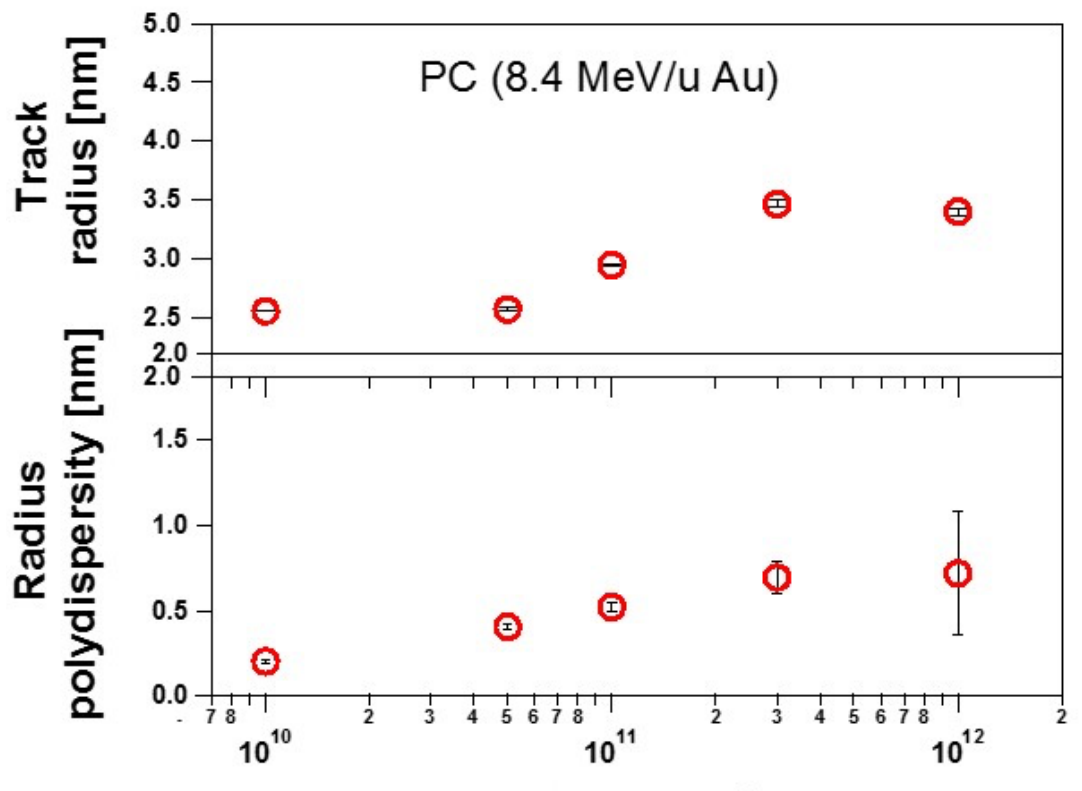

Fluence [ions $/ \mathrm{cm}^{2}$ ]

Fig. 4: Average track radii (a) and polydispersity (b) in PC (without chemical etching). Applied fluences are between $1 \times 10^{10}$ and $1 \times 10^{12} \mathrm{ions} / \mathrm{cm}^{2}$.

Figure 4 shows the track radii and the radius polydispersity for the different fluences. The track radius becomes larger with increasing fluence. The decrease in the strength of the oscillations is evident for higher fluences, resulting in an increase of the radius polydispersity. To asses if this effect is caused by the overlap of ion tracks, the area coverage A of the polymer was estimated using [23]

$$
A=1-\exp \left(-\pi R^{2} N\right)
$$

where the irradiation fluence is expressed as track density $N$ and the fitted track radius is inserted as $\mathrm{R}$. The area coverage is about $30 \%$ at $1 \times 10^{12} \mathrm{ion} / \mathrm{cm}^{2}$, and about $11 \%$ at $3 \times 10^{11}$ ions $/ \mathrm{cm}^{2}$. The area of track overlap as percentage of the total area covered with tracks is calculated to around $19 \%$ at $1 \times 10^{12}$ ions $/ \mathrm{cm}^{2}$, and about $6 \%$ at $3 \times 10^{11}$ ions $/ \mathrm{cm}^{2}$. Both quantities are shown in Fig. 5. Due to the low overlap at $3 \times 10^{11} \mathrm{ions} / \mathrm{cm}^{2}$, we conclude that the increasing track radius with ion fluence is not a direct result of the overlap when considering the SAXS measured track radius. One possible explanation for these could be the existence of a track halo 
that is defective but without noticeable density change. If an ion passes through the defective material of the halo it is possible that the damage cross-section visible by SAXS increases compared to track formation in un-damaged material. Apel et al. also indicates that in polymers, the track core is surrounded by a halo [27]. Steckenreiter et al. studied the chemical nature of $720-\mathrm{MeV} \mathrm{Kr}$ induced modifications in PC by FT-IR [12]. They found carbon triple bonds such as alkynes as a degradation product. The calculated ion track radius in which the alkynes are formed, increased from 3.0 and $3.4 \mathrm{~nm}$ for fluences between $1 \times 10^{12}$ and $6 \times 10^{12}$ ions $/ \mathrm{cm}^{2}$, which is similar to our observation.

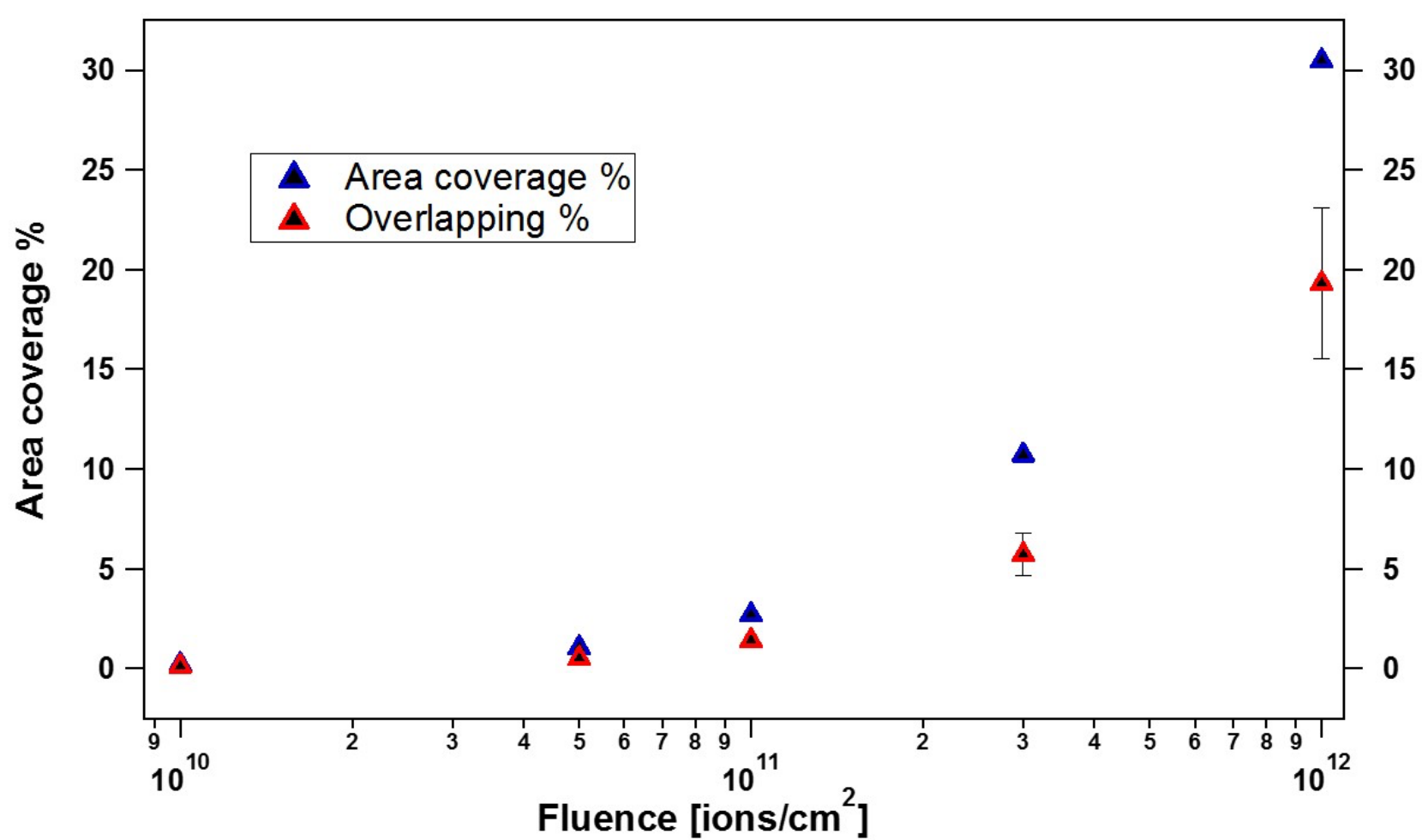

Fig. 5: Total area coverage (blue crosses) and track overlap (red triangles) with respect to the track covered area in \% for ion tracks in PC as a function of ion fluences. 


\section{Influence of etching time}

In the previous section, we showed that at a fluence of $5 \times 10^{10}$ ions $/ \mathrm{cm}^{2}$ tracks produced by 1.7 $\mathrm{GeV} \mathrm{Au}$ ion irradiation have a radius of $2.6 \pm 0.02 \mathrm{~nm}$. PC films irradiated with $2.2 \mathrm{GeV} \mathrm{Au}$ ion with a fluence of $5 \times 10^{10} / \mathrm{cm}^{2}$ were etched in a $3 \mathrm{M} \mathrm{NaOH}$ solutions at $55^{\circ} \mathrm{C}$ for different etching times. The SAXS patterns of etched PC films are shown in Figure 6 as a function of the scattering vector q. The SAXS pattern of 1 minute etched PC shows weak oscillation. With increasing etching time, the diameter of the pores grows and the oscillations become more pronounce and their frequency increases. The cylinder model was used to analyse the effective pore diameter and it shows an excellent agreement with the data.

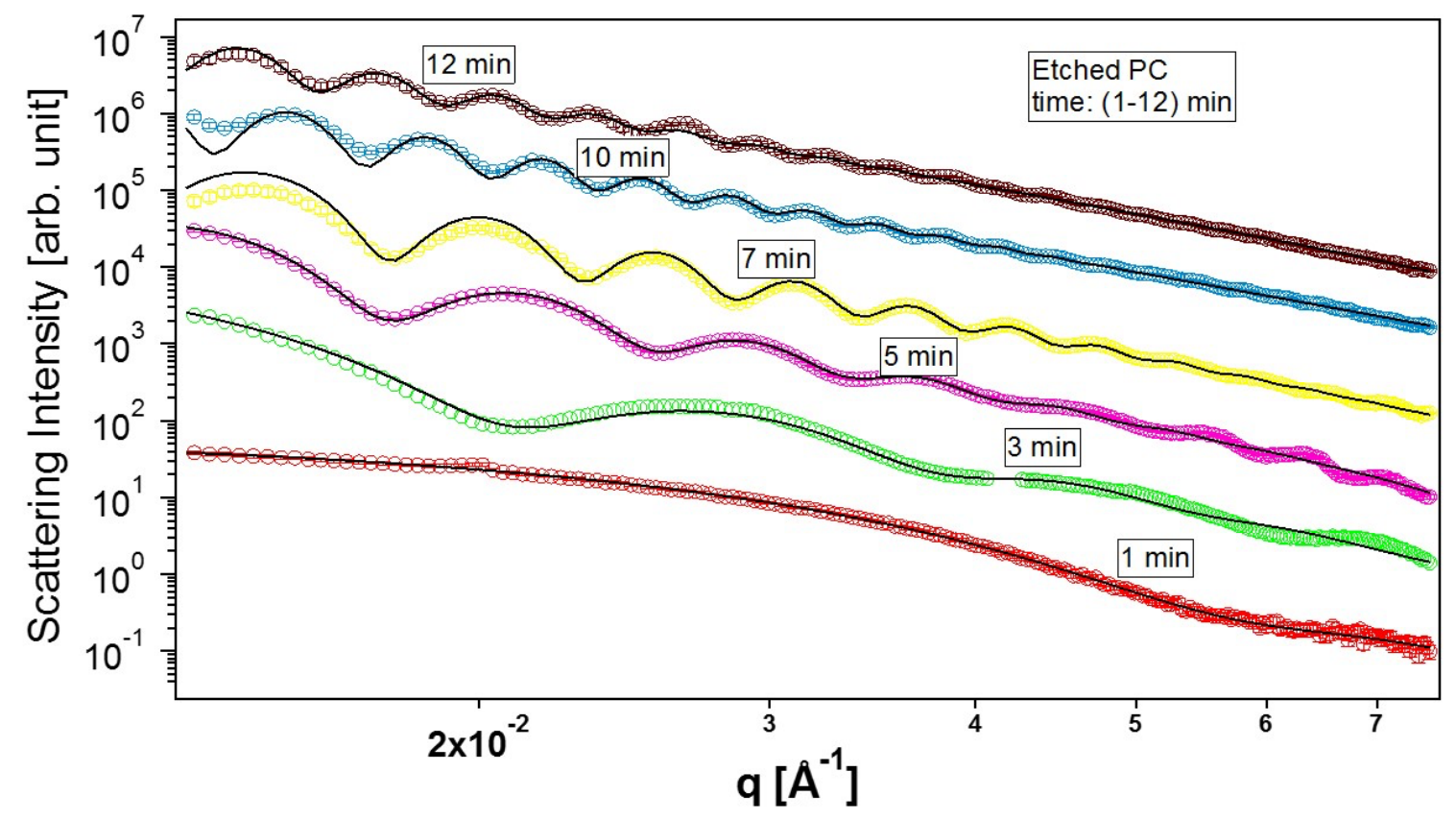

Fig. 6: SAXS patterns and fits (solid lines) for PC irradiated with $2.2 \mathrm{GeV} \mathrm{Au}$ at $5 \times 10^{10}$ ions $/ \mathrm{cm}^{2}$ after etching in $3 \mathrm{M} \mathrm{NaOH}$ at $55^{\circ} \mathrm{C}$ for different durations.

Figure 7 shows the evolution of the mean pore radius as a function of etching time up to 12 min, from which one can derive information on the radial etching rate. The pore radius is 7.2 $\pm 0.04 \mathrm{~nm}$ after $1 \mathrm{~min}$ etching and $103.4 \pm 0.01 \mathrm{~nm}$ after $12 \mathrm{~min}$ etching. The pore radius grows linearly with increasing etching time at a radial etch rate of $9.2 \pm 0.4 \mathrm{~nm} / \mathrm{min}$ as deduced 
from a linear fit. M.-C Clochard et al. investigated the pore radius for tracks PC produced with $0.63 \mathrm{MeV} / \mathrm{u} \mathrm{Pb}$ ions, finding radial etch rates around $13 \mathrm{~nm} / \mathrm{min}$ at $70^{\circ} \mathrm{C}, 2 \mathrm{M} \mathrm{NaOH}$, analysed by scanning electron microscopy (SEM) [28]. Sertova et al. investigated the track etching behaviour of PC foils exposed to $\mathrm{Pb}$ and $\mathrm{Ca}$ ions (analysed by FTIR and $\mathrm{SEM}$ ), indicating that the radial etch rate depends on the irradiation fluence [29]. Pepy et al. studied the pore structure of PC samples irradiated with $1.4 \mathrm{GeV}$ Xe ions (fluence: $2 \times 10^{8} \mathrm{ion} / \mathrm{cm}^{2}, \mathrm{dE} / \mathrm{dx}=8.7 \mathrm{MeV} / \mu \mathrm{m}$ ) for various etching times (etching conditions: $60^{\circ} \mathrm{C}, 5 \mathrm{M} \mathrm{NaOH}$ ) by small angle $\mathrm{x}$-ray scattering yielding a radial etching rate of about $12 \mathrm{~min} / \mathrm{nm} \mathrm{[20].}$

It is obvious that the etch rate depends on the etching conditions (e.g. etching time, concentration and temperature of the etchant). This and previous studies also show that the ion irradiation conditions, such as the ion mass and energy as well as the ion fluence can play an important role. SAXS with its short exposure times provides a method for systematic investigation of the large parameter space that determine the pore shapes and sizes during track etching.

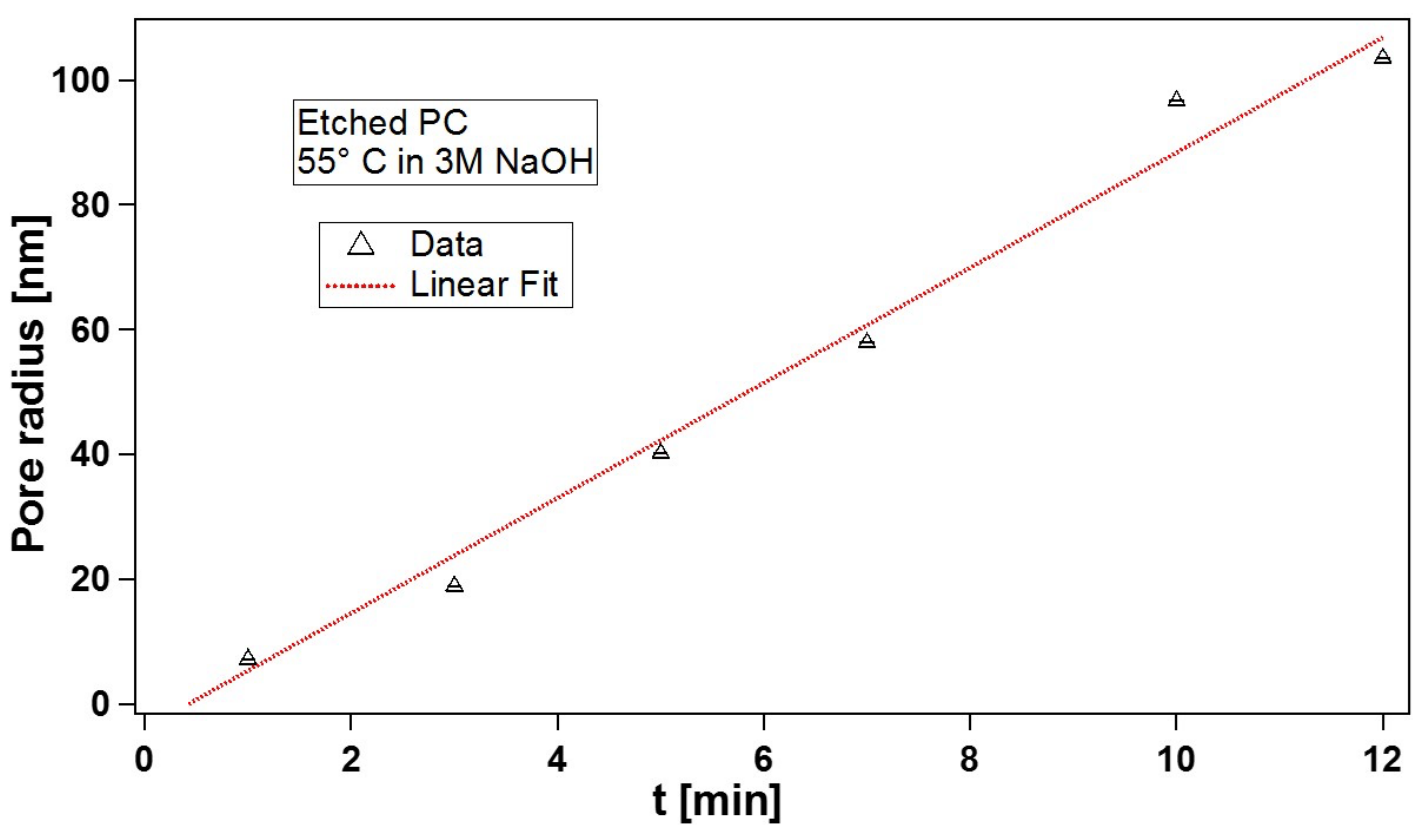

Fig. 7: Pore radius as a function of time during track etching in $3 \mathrm{M} \mathrm{NaOH}$ solution. The data result from SAXS measurements on PC foils irradiated with $2.2 \mathrm{GeV}$ Au at $5 \times 10^{10} \mathrm{ions} / \mathrm{cm}^{2}$. 


\section{Conclusions}

In this work, we used SAXS to determine radii of etched and un-etched ion tracks in polycarbonate foils. A hard cylinder model describes the SAXS data well, providing clear evidence for the cylindrical shape of the tracks with an aspect ratio of about 4,000. The corresponding ion track radii are in the range of $2.6-3.4 \mathrm{~nm}$ for ion fluences between $1 \times 10^{10}$ and $1 \times 10^{12}$ ions $/ \mathrm{cm}^{2}$. The increase in track radius with increasing fluence is consistent with the presence of a damaged halo around the track core measured by SAXS. Chemical etching of track in PC shown to proceed with a radial etching rate of around $9.2 \mathrm{~nm} / \mathrm{min}$ at $55^{\circ} \mathrm{C}, 3 \mathrm{M}$ $\mathrm{NaOH}$. We exposed that by using SAXS it is possible to perform a systematic investigation of etched tracks. In this context, we envision that the SAXS can provide a technology for investigation of the precise shape and size of nano-pores during in-situ etching experiments, where also the early evolution of pore formation can be followed.

\section{Acknowledgement}

The research was undertaken on the SAXS/WAXS beamline at the Australian Synchrotron. We acknowledge the DFG (HO 5722/1-1 and SCHL 384-17/1) and the Australian Research Council for financial support.

\section{Literature}

[1] U.H. Hossain, T. Seidl, W. Ensinger, Polymer Chemistry 5 (2014) 1001.

[2] D. Fink, Transport processes in ion-irradiated polymers, Springer, Heidelberg, 2004.

[3] D. Fink, P.S. Alegaonkar, A.V. Petrov, M. Wilhelm, P. Szimkowiak, M. Behar, D. Sinha, W.R. Fahrner, K. Hoppe, L.T. Chadderton, Nuclear Instruments and Methods in Physics Research Section B: Beam Interactions with Materials and Atoms 236 (2005) 11.

[4] M.E. Toimil-Molares, Beilstein J. Nanotechnol. 3 (2012) 860.

[5] M.G. Dhara, S. Banerjee, Progress in Polymer Science 35 (2010) 1022.

[6] N.M. Hansen, K. Jankova, S. Hvilsted, European Polymer Journal 43 (2007) 255. 
[7] M. Karlušić, M. Jakšić, M. Buljan, J. Sancho-Parramon, I. Bogdanović-Radović, N. Radić, S. Bernstorff, Nuclear Instruments and Methods in Physics Research Section B: Beam Interactions with Materials and Atoms 317, Part A (2013) 143.

[8] R.P. Joshi, K. Hareesh, A. Bankar, G. Sanjeev, K. Asokan, D. Kanjilal, S.S. Dahiwale, V.N. Bhoraskar, S.D. Dhole, Nuclear Instruments and Methods in Physics Research Section B: Beam Interactions with Materials and Atoms 384 (2016) 6.

[9] S. Asad Ali, R. Kumar, F. Singh, P.K. Kulriya, R. Prasad, Nuclear Instruments and Methods in Physics Research Section B: Beam Interactions with Materials and Atoms 268 (2010) 1813.

[10] L. Singh, K.S. Samra, Nuclear Instruments and Methods in Physics Research Section B: Beam Interactions with Materials and Atoms 263 (2007) 458.

[11] F. Dehaye, E. Balanzat, E. Ferain, R. Legras, Nuclear Instruments and Methods in Physics Research Section B: Beam Interactions with Materials and Atoms 209 (2003) 103.

[12] T. Steckenreiter, E. Balanzat, H. Fuess, C. Trautmann, Nuclear Instruments and Methods in Physics Research Section B: Beam Interactions with Materials and Atoms 151 (1999) 161.

[13] D. Severin, PhD thesis, Philipps University of Marburg, 2008.

[14] K.N. B. Afra, M. D. Rodriguez, T. Bierschenk, C. Trautmann, S. Mudie, and P. Kluth, Physical Review B 90 (2014) 224108.

[15] P.K. W. Li, D. Schauries, M. D. Rodriguez, M. Lang, F. Zhang, M. Zdorovets, C. Trautmann, and R. C. Ewing, American Mineralogist 99 (2014) 1127.

[16] M.L. D. Schauries, O. H. Pakarinen, S. Botis, B. Afra, M. D. Rodriguez, F. Djurabekova, K. Nordlund, D. Severin, M. Bender, W. X. Li, C. Trautmann, R. C. Ewing, N. Kirby, and P. Kluth, "Temperature dependence of ion track formation in quartz and apatite”, Journal of Applied Crystallography 46 (2013) 1558-1563, Journal of Applied Crystallography 46 (2013) 1558.

[17] R.G. T. Bierschenk, B. Afra, M. D. Rodriguez, D. Schauries, S. Mudie, O. H. Pakarinen, F. Djurabekova, K. Nordlund, O. Osmani, N. Medvedev, B. Rethfeld, M. C. Ridgway, and P. Kluth, , Physical Review B 88 (2013) 174111.

[18] T.B. M. C. Ridgway, R. Giulian, B. Afra, M. D. Rodriguez, L. L. Araujo, A. P. Byrne, N. Kirby, O. H. Pakarinen, F. Djurabekova, K. Nordlund, M. Schleberger, O. Osmani, N. Medvedev, B. Rethfeld, and P. Kluth Physical Review Letters 110 (2013) 245502. 
[19] C.S.S. P. Kluth, O. H. Pakarinen, F. Djurabekova, D.J. Sprouster, R. Giulian, M.C. Ridgway, A. P. Byrne, C. Trautmann, D. J. Cookson, K. Nordlund, M. Toulemonde, Physical Review Letters 101 (2008) 175503

[20] D. Schauries, M.D. Rodriguez, B. Afra, T. Bierschenk, C. Trautmann, S. Mudie, P. Kluth, Nuclear Instruments and Methods in Physics Research Section B: Beam Interactions with Materials and Atoms 365, Part B (2015) 573.

[21] G. Pepy, P. Boesecke, A. Kuklin, E. Manceau, B. Schiedt, Z. Siwy, M. Toulemonde, C. Trautmann, Journal of Applied Crystallography 40 (2007) s388.

[22] J.F. Ziegler, M. Ziegler, J. Biersack, Nuclear Instruments and Methods in Physics Research Section B: Beam Interactions with Materials and Atoms 268 (2010) 1818.

[23] P. Kluth, O.H. Pakarinen, F. Djurabekova, R. Giulian, M.C. Ridgway, A.P. Byrne, K. Nordlund, Journal of Applied Physics 110 (2011) 123520.

[24] B. Afra, M. Lang, M.D. Rodriguez, J. Zhang, R. Giulian, N. Kirby, R.C. Ewing, C. Trautmann, M. Toulemonde, P. Kluth, Physical Review B 83 (2011) 064116.

[25] J. Ilavsky, P.R. Jemian, Journal of Applied Crystallography 42 (2009) 347.

[26] Á.R. Páramo, F. Sordo, D. Garoz, O. Peña-Rodríguez, A. Prada, J. Olivares, M.L. Crespillo, J.M. Perlado, A. Rivera, Nuclear Instruments and Methods in Physics Research Section B: Beam Interactions with Materials and Atoms.

[27] P. Apel, A. Schulz, R. Spohr, C. Trautmann, V. Vutsadakis, Nuclear Instruments and Methods in Physics Research Section B: Beam Interactions with Materials and Atoms 146 (1998) 468.

[28] M.C. Clochard, T.L. Wade, J.E. Wegrowe, E. Balanzat, Nuclear Instruments and Methods in Physics Research Section B: Beam Interactions with Materials and Atoms 265 (2007) 325.

[29] N. Sertova, E. Balanzat, M. Toulemonde, C. Trautmann, Nuclear Instruments and Methods in Physics Research Section B: Beam Interactions with Materials and Atoms 267 (2009) 1039. 